\title{
Dosimetric Evaluation of the Scanning Activity at the Regional Hospital of Kaolack (Senegal)
}

\author{
B. Ndong1, M. S. Djigo1, G. Akpo², E. A. L. Bathily¹, 0. Diop¹, A. R. Sanou1, A. K. Koutouan³,

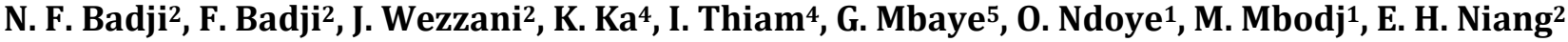 \\ ${ }^{1}$ Biophysics Laboratory, and Nuclear Medicine, Cheikh Anta Diop University, FMPO, Dakar, Senegal \\ ${ }^{2}$ Radiology and Medical Imaging Department of Aristide Le Dantec University Hospital, Cheikh Anta Diop University, Dakar, \\ Senegal \\ ${ }^{3}$ Biophysics Laboratory and Nuclear Medicine, UFR Medical Sciences, University Félix-Houphouet Boigny, Cocody, Abidjan, \\ Côte d'Ivoire \\ ${ }^{4}$ Radiothérapy Department of the National Hospital University Center, Dalal Jamm, Guédiaway, Dakar, Sénégal \\ ${ }^{5}$ Physics Pharmaceutical Laboratory, Cheikh Anta Diop University, FMPO, Dakar, Senegal \\ Email: ndongboucar73@yahoo.fr
}

How to cite this paper: Ndong, B., Djigo, M.S., Akpo, G., Bathily, E.A.L., Diop, O., Sanou, A.R., Koutouan, A.K., Badji, N.F., Badji, F., Wezzani, J., Ka, K., Thiam, I., Mbaye, G., Ndoye, O., Mbodj, M. and Niang, E.H. (2021) Dosimetric Evaluation of the Scanning Activity at the Regional Hospital of Kaolack (Senegal). Open Journal of Biophysics, 11, 351-358.

https://doi.org/10.4236/ojbiphy.2021.113012

Received: May 27, 2021

Accepted: July 17, 2021

Published: July 20, 2021

Copyright (c) 2021 by author(s) and Scientific Research Publishing Inc. This work is licensed under the Creative Commons Attribution International License (CC BY 4.0).

http://creativecommons.org/licenses/by/4.0/

\begin{abstract}
The aim of this study was to evaluate the dose delivered to patients during scannographic examinations at the Kaolack Regional Hospital (one of the 14 regions of Senegal located in the center-west of the country, $192 \mathrm{~km}$ from Dakar) and to compare these irradiation doses at diagnostic reference levels found in the literature in order to optimize our scanning protocols. To achieve this goal, we carried out a prospective study involving $218 \mathrm{CT}$ scans. These examinations focused on cerebral, thoracic, abdominopelvic and lumbar spine acquisitions made in adults and cerebral only in children. We compared the median values of dosimetric indicators (CTDIvol and DLP) per acquisition with NRDs in the literature. During the course of this study, we found a dosimetric ratio lower than that of the NRDs for thoracic, abdomino-pelvic and lumbar spine CT scans in adults and a significant dosimetric exceedance for brain scans in adults and in children. These results encourage us to extend these dosimetric evaluations to other hospital structures in order to establish rigorous monitoring of dosimetric indicators and to respect the principles of radiation protection and good practice.
\end{abstract}

\section{Keywords}

Dosimetry, CT, DRL, Senegal

\section{Introduction}

Computed tomography is based on the fact that different tissues in the body 
achieve differential X-ray attenuation. The relatively homogeneous beam at the entrance becomes inhomogeneous. This information, called a radiant image, forms a real image with an appropriate sensor. These are obtained at the cost of a certain irradiation of the patient which leads to more or less long-term biological effects. This is why it seems judicious to respect the contraindications, and all reasonable technical means must be implemented to reduce these irradiation doses as much as possible while maintaining the good contrast of the image [1]. Nowadays, there is an increased demand for sometimes unjustified CT scans. This leads to deleterious effects, the most frequently encountered in medicine being the stochastic effects. We could not establish thresholds as these effects are at low doses and are also random [2]. These repeated doses, compatible with cell survival, are at the origin of DNA alterations resulting in carcinogenesis for somatic cells and transmissible genetic alterations for germ cells [3]. Two studies were carried out in Senegal concerning DRLs. One was carried out at the CHNU of FANN by DIOP [4] and collaborators and focused on conventional radiology. The other study concerned the X-ray scanner, and was carried out at CHN Aristide in Le Dantec by El Madrouchi and collaborator [5]. These two studies required supplementation with a choice of appropriate parameters to answer the question of radiation protection of patients with reference levels requiring optimization [6].

It is for this purpose that the International Atomic Energy Agency as well as other similar organizations in the world such as EURATOM, have laid down the general principles of the protection of patients exposed to ionizing radiation during an act for diagnosis purposes. In addition to explaining the steps necessary for the radiation protection of patients, it recommends, to member states, the development and use of diagnostic reference levels (DRLs) for radio-diagnosis examinations in particular CT scan [7].

The aim of our work was to compare the irradiation doses delivered to our patients with computed tomography NRD values found in the literature in order to make corrections to our protocols when necessary.

\section{Materials and Methods}

\subsection{Material}

This was a prospective, descriptive and analytical study carried out over a period of 3 months from February 17 to May 17, 2020. The data collection was done at the medical imaging department of the EL HADJ IBRAHIMA NIASS regional hospital of Kaolack, city situated in the central west of Senegal. During the study period, we received 288 patients for CT examinations and have adopted the criteria set by decision $n^{\circ}$ 2019-DC-0667 of the Nuclear Safety Authority (ASN) of April 18, 2019 relating to the methods for evaluating the doses of ionizing radiation delivered to patients during an act of radiology [8]. After applying the inclusion criteria, five types of scanners were studied, depending on the body area explored and the age category. 
For the adult population, we performed 102 brain CT scans, 31 thoracic CT scans, 43 abdomino-pelvic and 32 lumbar spine CT scans.

For the pediatric population, we performed 10 brain CT scans in a population of children from 5 to 10 years old with a weight between 20 and $30 \mathrm{~kg}$.

\subsection{Methodology}

The examinations were carried out on a multi-slice helical scanner from SIEMENS model 2010 (Muenchen, Germany), equipped with 16 strips.

The scanner incorporates an irradiation dose reduction technique (CARE Dose-4D) and the load can thus vary from 30 to $500 \mathrm{~mA}$.

The CT presented in post-acquisition a dosimetric report on which appeared the doses delivered expressed in CTDI vol and in DLP for each acquisition and for the entire examination, as well as the length explored. The parameters that allowed the study to be carried out were voltage $(\mathrm{kV})$, load $(\mathrm{mA})$, acquisition thickness, rotation speed, collimation $(\mathrm{mm})$ and expected length. These examinations were carried out according to predefined standard protocols. The voltage was set at $130 \mathrm{kV}$ for adults and $110 \mathrm{kV}$ for children. The load adopted was $220 \mathrm{~mA}$ for brain acquisition and other types of acquisitions with automatic milliamperage modulation. This could be lengthened or shortened on the topogram, compared to the length provided for in the protocol.

As for the dosimetric parameters, we studied the volumetric CT dose index (CTDI vol.). The length explored was modifiable as was the dose length product (DLP). Statistical analysis of these data was performed by dedicated statistical analysis software SPSS, version 18 and graphical representations made by Microsoft Excel 365 software

\section{Results}

\subsection{Dosimetric Evaluation in Adults}

\subsubsection{Brain CT}

The value of the flight CTDI was constant at $58.3 \mathrm{mGy}$. The median value of the lengths explored was $188.5 \mathrm{~mm}$ with extremes ranging from $159.5 \mathrm{~mm}$ to 341.5 $\mathrm{mm}$ with a ratio. The 75th percentile and the 25 th percentile are estimated at $211.25 \mathrm{~mm}$ and $177 \mathrm{~mm}$ respectively, i.e. a $75 \mathrm{th} / 25$ th percentile ratio estimated at 1.19. For DLP (Figure 1), the median was $1098.94 \mathrm{mGy} \cdot \mathrm{cm}$, with a standard deviation of $270.95 \mathrm{mGy} \cdot \mathrm{cm}$ with extremes ranging from 929.87 to 1990.92 $\mathrm{mGy} \cdot \mathrm{cm}$. The 75 th/25th percentiles were estimated at 1257.07 and 1031.91 $\mathrm{mGy} \cdot \mathrm{cm}$ respectively, i.e. a $75 \mathrm{th} / 25$ th percentile ratio of 1.21 .

\subsubsection{Thoracic CT}

The median value of the flight CTDIs was $6.13 \mathrm{mGy}$ with a standard deviation of $2.55 \mathrm{mGy}$ and extremes of 2.85 and $14.4 \mathrm{mGy}$. The 75th/25th percentiles are respectively estimated at 8.22 and $5.19 \mathrm{mGy}$, i.e. a 75 th/25th percentile ratio corresponding to 1.58. As for the median value of the lengths explored; it was estimated at $356.4 \mathrm{~mm}$ with a standard deviation of $97.4 \mathrm{~mm}$ and extreme values of 


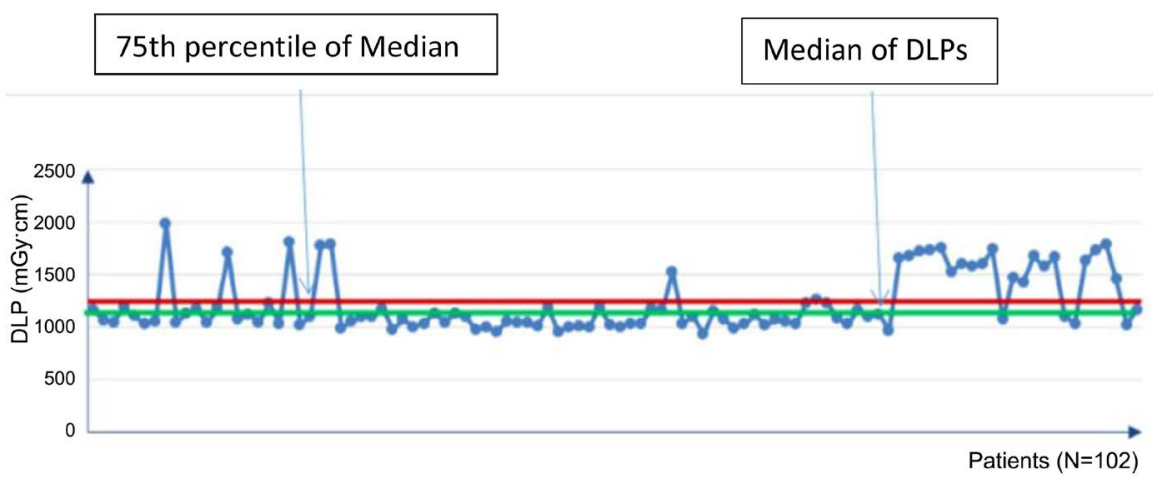

Figure 1. Distribution of PDL values for brain CT scan in adults.

269.4 and $734.7 \mathrm{~mm}$. The 75th/25th percentiles are estimated at 384.7 and 330.9 respectively, i.e. a 75 th/25th percentile ratio of 1.16 .

For DLP (Figure 2), the median was $218.58 \mathrm{mGy} \cdot \mathrm{cm}$, with a standard deviation of $96.1 \mathrm{mGy} \cdot \mathrm{cm}$ and extremes of 91.95 and $444.1 \mathrm{mGy} \cdot \mathrm{cm}$. The $75 \mathrm{th} / 25 \mathrm{th}$ percentiles were estimated at $355.43 \mathrm{mGy} \cdot \mathrm{cm}$ and $188.29 \mathrm{mGy} \cdot \mathrm{cm}$ respectively, i.e. a 75 th $/ 25$ th percentile ratio of 1.88 .

\subsubsection{Abdomino-Pelvic Scanner}

The median value of the flight CTDIs was $5.61 \mathrm{mGy}$ with a standard deviation of $1.3 \mathrm{mGy}$ and extremes of 4.26 and $9.65 \mathrm{mGy}$. The 75th and 25th percentiles are respectively estimated at 6.78 and $4.26 \mathrm{mGy}$, i.e. a $75 \mathrm{th} / 25$ th percentile ratio corresponding to 1.3. As for the median value of the lengths explored; it was estimated at $498.7 \mathrm{~mm}$ with a standard deviation of $44.84 \mathrm{~mm}$ and extreme values of 438.2 and 679.2 . The 75 th/25th percentiles are estimated at 520.7 and 470.7 $\mathrm{mm}$ respectively, i.e. a 75 th/25th percentile ratio of 1.1 .

For the DLP (Figure 3), the median was $281.91 \mathrm{mGy} \cdot \mathrm{cm}$, with a standard deviation of $71.45 \mathrm{mGy} \cdot \mathrm{cm}$ and extremes ranging from 200.27 to 503.38 $\mathrm{mGy} \cdot \mathrm{cm}$. The $75 \mathrm{th} / 25$ th percentiles were estimated at $333.3 \mathrm{mGy} \cdot \mathrm{cm}$ and 241.74 $\mathrm{mGy} \cdot \mathrm{cm}$ respectively, i.e. a $75 \mathrm{th} / 25$ th percentile ratio of 1.37 .

\subsubsection{CT Scan of the Lumbar Spine}

The median value of the flight CTDIs was $10.39 \mathrm{mGy}$ with a standard deviation of $3.45 \mathrm{mGy}$ and extremes ranging from 5.05 to $21.09 \mathrm{mGy}$. The 75th/25th percentiles are respectively estimated at 11.82 and $8.91 \mathrm{mGy}$, i.e. a 75th/25th percentile ratio corresponding to 1.32 . As for the median value of the lengths explored; it was estimated at $285.45 \mathrm{~mm}$ with a standard deviation of $112.79 \mathrm{~mm}$ and extreme values varying from 230.2 to $616 \mathrm{~mm}$. The 75th and 25th percentiles are estimated at 327.82 and $268.3 \mathrm{~mm}$ respectively, i.e. a 75 th $/ 25$ th percentile ratio of 1.22 .

For DLP (Figure 4), the median was $310.55 \mathrm{mGy} \cdot \mathrm{cm}$, with a standard deviation of $159.12 \mathrm{mGy} \cdot \mathrm{cm}$ and extremes ranging from 169.04 to $876.43 \mathrm{mGy} \cdot \mathrm{cm}$. The 75th/25th percentiles were estimated at $426.32 \mathrm{mGy} \cdot \mathrm{cm}$ and $245.09 \mathrm{mGy} \cdot \mathrm{cm}$ respectively, i.e. a 75 th/25th percentile ratio of 1.73 . 


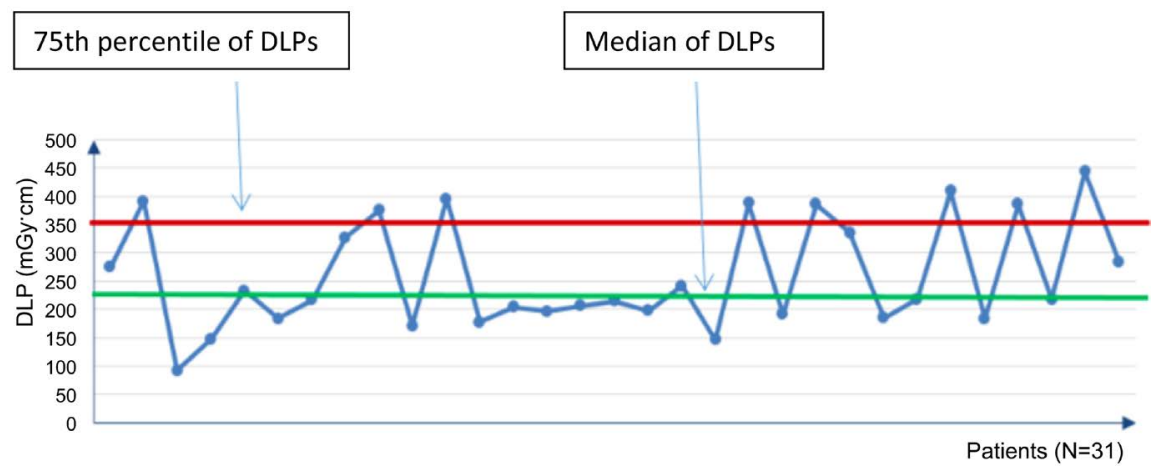

Figure 2. Distribution of DLP for chest CT scan in adults.

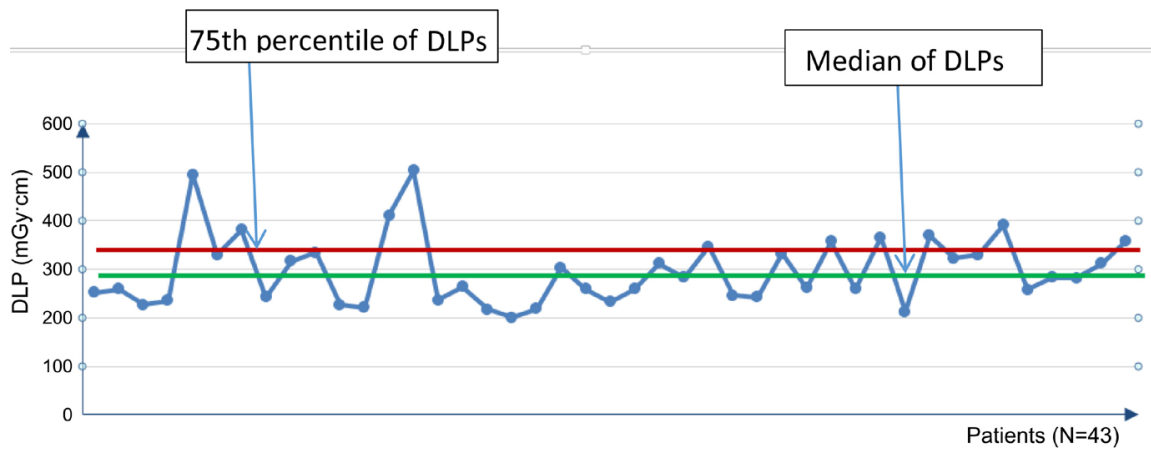

Figure 3. Distribution of DLP for abdominopelvic CT scan in adults.

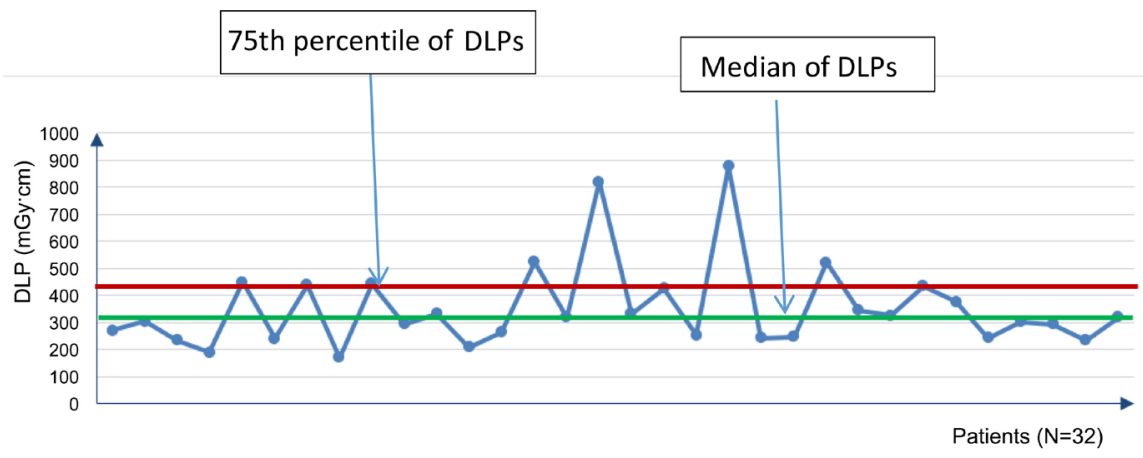

Figure 4. Distribution of PDL for CT scan of the lumbar spine in adults.

\subsection{Dosimetric Evaluation of the Brain Scan in Children}

The distribution of CTDI-vol values by brain scan acquisition had a median value of $25.93 \mathrm{mGy}$ with a standard deviation of $3.31 \mathrm{mGy}$ and extreme values of 22.94 and $31.52 \mathrm{mGy}$. The values of the 75th/25th percentiles were respectively estimated at 29.32 and $23.73 \mathrm{mGy}$, i.e. a 75 th/25th percentile ratio corresponding to 1.23 .

As for the median value of the lengths explored; it was estimated at $290.1 \mathrm{~mm}$ with a standard deviation of $41.38 \mathrm{~mm}$ and extreme values varying from 199.6 to $316.1 \mathrm{~mm}$. The 75th/25th percentiles are estimated at 304.72 and $262.97 \mathrm{~mm}$ respectively, i.e. a 75 th/25th percentile ratio of 1.15 .

For DLP (Figure 5), the median was $743.57 \mathrm{mGy} \cdot \mathrm{cm}$, with a standard deviation 


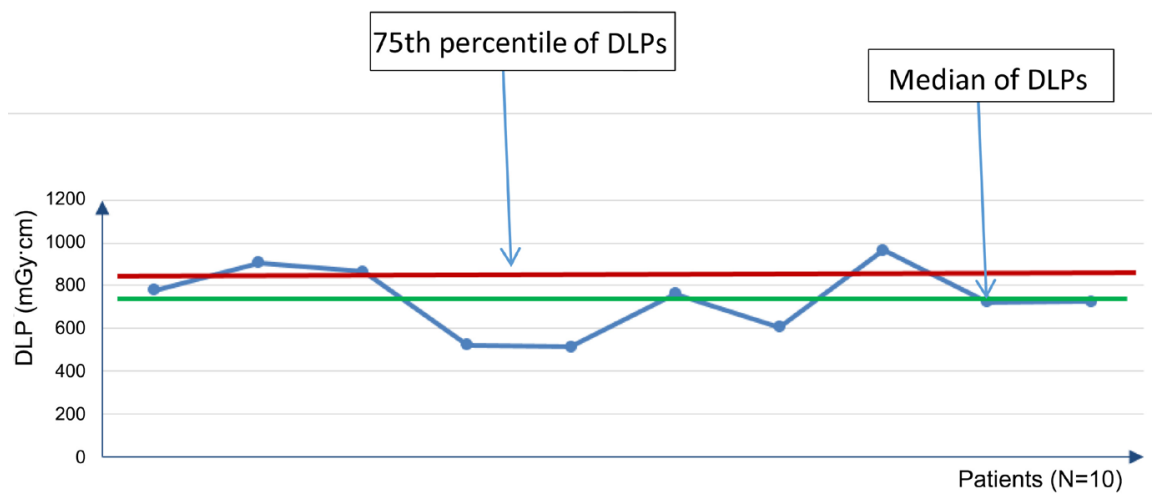

Figure 5. Distribution of DLPs for the brain scan in children.

of $153.87 \mathrm{mGy} \cdot \mathrm{cm}$ and extremes ranging from 513.63 to $964.76 \mathrm{mGy} \cdot \mathrm{cm}$. The 75th/25th percentiles were estimated at $843.41 \mathrm{mGy} \cdot \mathrm{cm}$ and $633.89 \mathrm{mGy} \cdot \mathrm{cm}$ respectively, i.e. a 75 th/25th percentile ratio of 1.33 .

\section{Discussion}

\subsection{Dosimetric Evaluation in Adults}

\subsubsection{Brain Scanner}

The value of the flight CTDI was constant at $58.3 \mathrm{mGy}$, higher than the NRD value in the USA [9] which is $56 \mathrm{mGy}$, that in Belgium [10] which is $50 \mathrm{mGy}$ and that in France [8] which is $46 \mathrm{mGy}$. The median value of DLP was 1098.94 $\mathrm{mGy} \cdot \mathrm{cm}$, higher than the NRD value in the USA [9] which is $962 \mathrm{mGy} \cdot \mathrm{cm}$, that in Belgium [10] $800 \mathrm{mGy} \cdot \mathrm{cm}$ and that in France [8] $850 \mathrm{mGy} \cdot \mathrm{cm}$.

As in our study and with this type of brain examination carried out in adults, the only parameter modifiable by the manipulator technician was the length explored and, moreover, the irradiation dose reduction software (CARE Dose-4D) did not work, this could explain the superiority of our values of CTDI and DLP compared to those found in the literature. We also observed that the median value of the lengths explored was $188.5 \mathrm{~mm}$ and is much greater than the length provided for by the predefined protocol $(150 \mathrm{~mm})$, with an inclusion in the field of exploration of anatomical areas not interested in the desired study, hence the need for compliance for this type of examination. For this, it seems judicious to us to limit ourselves to the irradiation field, to the anatomical zone useful for the study and also to study the possibility of integrating the dose reduction software for this type of examination.

\subsubsection{Thoracic, Abdominopelvic and Lumbar Spine Scans}

The median values of CTDIvol were lower than the values of NRDs in the USA, Belgium and France.

The median values of the lengths explored were relatively high compared to the length provided for by the protocol, especially for scans of the lumbar spine where several of our examinations went back to the dorsal vertebral level or covered the entire pelvis. 
We insisted with the manipulator technicians on the importance of respecting the acquisition lengths. The normal height of acquisition for the lumbar spine should extend from the twelfth dorsal vertebra to the sacroiliac joints.

The median DLP values were lower than the NRD values in the USA, Belgium and France.

Although the lengths explored are relatively high, the use of the irradiation dose reduction software (CARE Dose-4D), allowing the automatic modulation of the load according to the different regions crossed by the X-ray beam, means that the median values of the vol and DLP CTDIs remain lower than the NRD values [11].

\subsection{Dosimetric Evaluation of the Brain Scan in Children}

The median value of CTDIvol was $25.93 \mathrm{mGy}$, lower than the value of NRD in Canada [12] which is $51.5 \mathrm{mGy}$, that in Belgium [8] which is $40 \mathrm{mGy}$ and also that in France [8] which is $26 \mathrm{mGy}$.

The median value of the lengths explored was $290.1 \mathrm{~mm}$, much too high compared to the length provided for by the protocol $(150 \mathrm{~mm})$.

The median value of DLP was $843.41 \mathrm{mGy} \cdot \mathrm{cm}$, higher than the value of NRD in Canada [12] which is $692 \mathrm{mGy} \cdot \mathrm{cm}$, that in Belgium [10] which is $660 \mathrm{mGy} \cdot \mathrm{cm}$ and also that in France [8] which is $470 \mathrm{mGy} \cdot \mathrm{cm}$.

Despite the use of radiation dose reduction software (CARE Dose-4D) for this type of scanner, the DLP was significantly higher than the NRD values. This can be explained by a lack of training of our technicians, whether for acquisition techniques, with inclusion in the field of exploration of anatomical areas not interested in the desired study, or radiation protection rules for the patient.

\section{Conclusions}

The improvement of the scanning practice requires, first of all, a good knowledge of the fundamental principles of radiation protection applied to the medical field: the justification of the clinical indication and the choice of the radiological examination, optimization by informed management acquisition parameters to achieve the compromise between lower dose of irradiation and better image quality, known by the acronym "ALARA" (As Low As Reasonably Achievable) and finally substitution when the limitation is not beneficial to the patient.

In Senegal, it would be useful to introduce legislation that requires an assessment of the radiation doses delivered to patients during diagnosis and interventional radiological examinations against national reference values. These evaluations would be periodic and monitored and corrective actions would be imposed as needed.

The transposition of the dosimetric record in our reports should be compulsory. Relevant information is DLP for any exposure and CTDIvol for pelvic exposures in women of childbearing age and in pregnant women after justified 
exposure.

The initial and continuing training in radiation protection of the various stakeholders must be an ethical or even legal obligation.

\section{Conflicts of Interest}

The authors declare no conflicts of interest regarding the publication of this paper.

\section{References}

[1] Institut de Radioprotection et de Sureté Nucléaire (2014) Exposition de la population française aux rayonnements ionisants liée aux actes de diagnostic médical en 2012. Report No.: Rapport PRP-HOM N²014-6. INRS, Paris.

[2] Comité scientifique des Nations Unies pour l'étude des effets des rayonnements ionisants (2000) Rapport à l'Assemblée générale, avec annexes scientifiques Rapport UNSCEAR, 2000; A/55/46. ISSN 0255-1381.

[3] Cordoliani, Y.S. and Foehrenbach, H. (2008) Radioprotection en milieu médical. Principes et mise en pratique. 2e édition. Elsevier-Masson, Issy-les-Moulineaux.

[4] DIOP A. (2015) La radioprotection: éTude préliminaire des niveaux de référence diagnostique en radiologie conventionnelle, mémoire de master II de physique atomique et nucléaire à l'UCAD, FMPO, 2015, côte: mems 2019-0851.

[5] El Madrouchi, I. (2019) Evaluation des doses délivrées: scanner 64 barrettes, du centre hôspitalo-universitaire Aristide de Le Dantec, mémoire pour l'obtention du diplôme d'études spécialisé de radiodiagnostic et imagerie médicale à l'UCAD en FMPO, $\mathrm{N}^{\circ} 258$.

[6] Commission internationale de protection radiologique (2007) Protection radiologique en médecine. Publication CIPR 103. CIPR, London.

[7] Communauté européenne de l'énergie atomique: Directive 97/43 du conseil du 30 juin 1997 (1997) Relative à la protection sanitaire des personnes contre les dangers des rayonnements ionisants lors d'expositions à des fins médicales. EURATOM, Paris.

[8] Journal Officiel de la République Française (2019) Arrêté du 23 mai 2019 portant homologation de la décision no 2019-DC-0667 de l'Autorité de sûreté nucléaire du 18 avril 2019 relative aux modalités d'évaluation des doses de rayonnements ionisants délivrées aux patients lors d'un acte de radiologie, de pratiques interventionnelles radioguidées ou de médecine nucléaire et à la mise à jour des niveaux de référence diagnostiques associés. JORF 30 Mai 2019.

[9] Kalpana, M.K., Priscilla, F.B., Debapriya, S.., Mythreyi, B.-C., Laura, P.C. and Richard, L.M. (2017) U.S. Diagnostic Reference Levels and Achievable Doses for 10 Adult CT Examinations. Radiology, 284, 120-133. https://doi.org/10.1148/radiol.2017161911

[10] Moniteur Belge (2020) Neuvième itération pour les examens CT (01/11/2018$31 / 10 / 2019)$. Niveaux de référence diagnostiques nationaux en radiologie. MB du 10 avril 2020.

[11] Hara, A.K., Wellnitz, C.V., Paden, R.G., Pavlicek, W. and Sahani, D.V. (2013) Reducing Body CT Radiation Dose: beyond Just Changing the Numbers. AJR American Journal of Roentgenology, 201, 33-40. https://doi.org/10.2214/AJR.13.10556

[12] Santé Canada (2016) sondage canadien en tomodensitométrie-Niveaux de référence diagnostiques nationaux. 14 juin 2016. 